Faculdade de Ciências Econômicas UFRGS

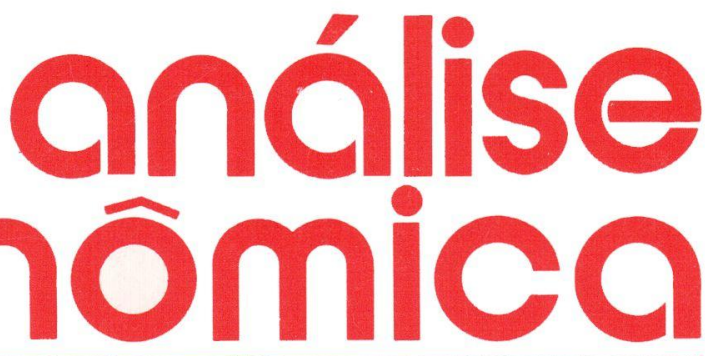

- PROgRAMA dE ESTABILIZAÇÃo DO GOVERNO COLLOR: CENTO E DEZ DIAS DEPOIS

Yeda Rorato Crusius

- SEGURO-DESEMPREGO E SUA INTEGRAÇÃO COM O SISTEMA NACIONAL DE EMPREGO José Paulo Zeetano Chahad

- RENDIMENTOS DECRESCENTES E PREÇO DO CAPITAL

Paolo Sylos Labini

- MARK-UP E DESTRUIÇÃO CRIADORA

Flávio Vasconcellos Comim

- TEORIA MONETÁRIA DE KEYNES Fernando Ferrari Filho

- ESTADO E PEQUENA PRODUÇÃO José Juliano de Carvalho Filho Ana Maria Castelo

- RACIONALIZAÇÃo DA PRODUÇÃo E ENSINO PROFISSIONAL (RS: 1889-1930) Sanara Jatahy Pesavento

- CONTRIBUICÕ̃ES À TEORIA DA LOCALIZAÇÃO INDUSTRIAL

Ruy Aguiar da Silva Leme

- POlaRizaÇÃo E deśolarizaÇÃo INDUSTRIAL NO BRASIL E NO RIO GRANDE DO SUL

Nali de Jesus de Souza
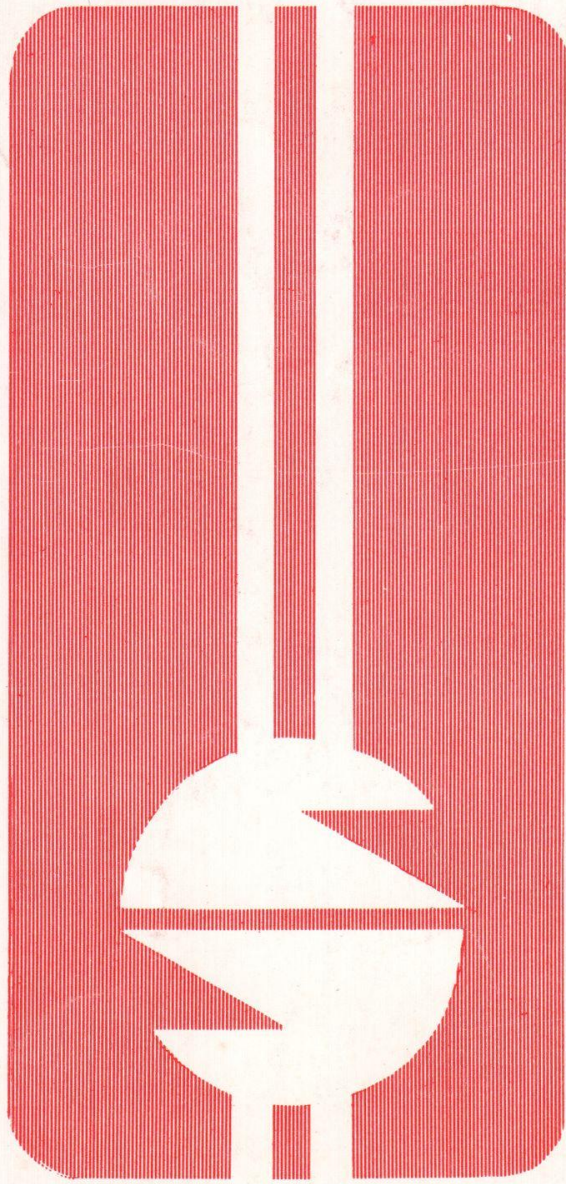
UNIVERSIDADE FEDERAL DO RIO GRANDE DO SUL

Reitor. Prof. Tuiskon Dick

FACULDADE DE CIÊNCIAS ECONÔMICAS

Diretor. Prof. Walter Meucci Nique

CENTRO DE ESTUDOS E PESQUISAS ECONÔMICAS

Diretor: Reinaldo Ignacio Adams

DEPARTAMENTO DE CIÉNCIAS ECONÔMICAS

Chefe: Prof. Pedro Cezar Dutra Fonseca

CURSO DE PÓS-GRADUAÇÃO EM ECONOMIA

Coordenador. Prof. Nali de Jesus de Souza

CURSO DE PÓS-GRADUAÇĀO EM ECONOMIA RURAL

Coordenador. Prof. Atos Freitas Grawunder

CONSELHO EDITORIAL: Achyles Barcelos da Costa, Aray Miguel Feldens, Atos Freitas Grawunder, Carlos Augusto Crusius, Ernani Hickmann, João Rogério Sanson, Juvir Luiz Mattuella, Maria Imilda da Costa e Silva, Nali de Jesus de Souza, Nuno Renan Lopes de Figueiredo Pinto, Otília Beatriz Kroeff Carrion, Otto Guilherme Konzen, Paulo Alexandre Spohr, Pedro Cezar Dutra Fonseca, Reinaldo Ignacio Adams, Roberto Camps Moraes, Valter José Stülp, Yeda Rorato Crusius, David Garlow (Wharton Econometrics Forecasts Association, E.U.A.), Edgar Augusto Lanzer (UFSC), Eleutério F.S. Prado (USP), Fernando Holanda Barbosa (FGV/RJ), Gustavo Franco (PUC/RJ), Joaquim Pinto de Andrade (UnB), Juan H. Moldau (USP), Werner Baer (Univ. de Illinois, E.U.A.).

COMISSÃO EDITORIAL: Atos Freitas Grawunder, Pedro Cezar Dutra Fonseca, Reinaldo Ignacio Adams e Roberto Camps Moraes.

EDITOR: Nali de Jesus de Souza.

SECRETARIA: Maria Ivone de Mello (normalização), Vanete Ricacheski (revisão de textos), Zélide Bregalda (Secretária).

FUNDADOR: Prot. Antônio Carlos Santos Rosa.

Os materiais publicados na revista Análise Econômica são de exclusiva responsabilidade dos autores. É permitida a reprodução total ou parcial dos trabalhos, desde que seja citada a fonte.

Aceita-se permuta com revistas congêneres. Aceitam-se, também, livros para elaboração de resenhas ou recensões.

Toda correspondência, material para publicação, assinaturas e permutas devem ser cirigidos ao seguinte destinatário:

PROF. NALI DE JESUS DE SOUZA

Revista Análise Econômica

Av. João Pessoa, 52

90.040 - PORTO ALEGRE (RS), BRASIL

Telefone: 25-58-44 ramal 33 


\section{POLARIZAÇÃO E \\ DESPOLARIZAÇÃO INDUSTRIAL NO BRASIL \\ E NO RIO GRANDE DO SUL}

Nali de Jesus de Souza'

\section{SINOPSE}

Este trabalho tem como objetivo examinar a hipótese da reversão cia polarização industrial no Brasil, desde o início da década de setenta. Usando o produto interno bruto industrial, yerado nas diferentes regiōes do País, incluindo os principais centros urbanos, constata-se a concentração industrial em São Paulo até 1968, quando atinge o máximo, para declinar até o presente. A despolarização ocorre igualmente no RS. A perda líquida de indústrias de Porto Alegre para a Região Metropolitana e para o interior do Estado ocorre desde o inicio dos anos setenta. Conclui-se que a despolarização é um fenômeno natural do mercado, mas os incentivos fiscais concedidos na periferia aceleram esse processo, tornando-o precoce, como parece ser o caso do RS.

\section{1 - CRESCIMENTO POLARIZADO}

O crescimento econômico efetua-se mais intensamente em alguns pontos do espaço, concentrando-se em algumas atividades. $O$ mesmo

1 Professor Titular do Departarrento de Ciências Econônicas $\Theta$ do Curso de Pós-Graduação em Economia da UFRGS; pesquisador do IEPE. O autor agradece aos professores Pedro C.D. Fonseca e Pedro S. Bandeira pelos comentários efetuados, eximindo-os, todavia, de eventuais erros rem anescentes no texto.

\begin{tabular}{|l|l|l|l|l|}
\hline ANÁLISE ECONÔMICA & ANO 8 & №13 & MARÇO/90 & p.173-191 \\
\hline
\end{tabular}


ocorre com a localização das populaçōes, que se estabelecem, via de regra, às margens dos rios, junto aos portos ou no interior de àreas com terras férteis, próprias ao cultivo de alimentos. Essa tendência à concentração das atividades foi observada por Smith, em 1776, quando discutia a divisão do trabalho (1983, p.53) e por Marshall, em 1890, quando criou o termo "economias externas" (Marshall, 1982, p.231). A concentração de firmas da mesma indústria, em uma dada localidade, gera ganhos que são internalizados pelas empresas da área, benefícios que estariam ausentes nas localizações dispersas.

O livre jogo das forças de mercado provoca, pois, a concentração das firmas no espaço. O crescimento econômico, como afirma Perroux (1977), não aparece em toda a parte ao mesmo tempo, mas se manifesta em alguns pontos, ou pólos ae crescimento, para difundir-se mais tarde, através de diversos canais, em toda a economia.

O pressuposto de Perroux é que existem mecanismos de difusão dos benefícios do crescimento polarizado, em todo o espaço, de forma instantânea e sem custos. No longo prazo, o próprio mercado provoca um processo de despolarização, ou crescimento mais do que proporcional da periferia em relação ao centro, pelo surgimento de deseconomias externas neste último e pela melhoria das vantagens comparativas em beneficio da periferia. ${ }^{2}$

Não havendo a difusão do crescimento no espaço, a partir da incústria motriz, geradora de efeitos de encadeamento e economias externas em yeral (ver Souza, 1988), descie o início do processo de polarização, o crescimento efetua-se com profundas desigualdades regionais. Os efeitos regressivos tornando-se superiores aos efeitos propulsivos (Myrdal, 1968, p.57), o crescimento do centro efetua-se em cietrimento das regiões periféricas. Ocorrendo o contrário, em que os efeitos propulsores superam os efeitos regressivos, como afirma a teoria perrouxiana, o centro torna-se a "locomotiva" das regiões periféricas, conforme a expressão de Cano (1985). Assim sendo, o crescimento por pólos torna-se

\footnotetext{
2 Perroux nåo estabelece explicitamente essa hipótese. Para ele, o crescimento da periferia ocorre desde o inlcio do processo, como indução do próprio dinamismo do centro. Quem estabeleceu a dicotomia entre concentraçăo regional e posterior desconcentraçăo, mais claramente, foi Wiilliamson, em 1965. Utilizando indices de desigualdade de Kuznets (1963), para diversos paises, Williamson (1977, p.62) estudou a hipdtese de que as desigualdades entre regióes inicialmente aumentam, atingem um máximo e depois declinam. Em um gráfico, uma curva que representasse o grau de concentração espacial do crescimento económico, no tempo, teria a forma de um " $U$ " invertido. $O$ autor conclui que o ponto em que a desigualdade atinge um máximo é difficil de precisar e que a convergência regional tende a ocorrer nos países onde o capitalismo industrial apresenta-se mais avançado.
} 
positivo para o desenvolvimento do pais como um todo: basta implantarse a indústria motriz, adequada a seu meio, que não apenas o pólo principal se consolida, pela simples atração de firmas e indústrias satélites, via polarização tecnológica, geográfica e psicológica (Souza, 1989), como todas as demais regiões periféricas se beneficiam, através do aumento do comércio interregional.

No Brasil, essa foi a idéia dominante na década de cinqüenta, principalmente entre os que elaboraram o Plano de Metas. A preocupação era maximizar a internação das economias externas, através dos investimentos públicos e estrangeiros, soivretudo em São Paulo, e evitar a diluição cios efeitos de tais investimentos, com a dispersão dos mesmos em todo o espaço (Campos, 1952).

\section{FATOKES DO CRESCIMENTO POLARIZADO NO BRASIL.}

As ciesigualdades regionais no Brasil explicam-se por inúmeros fatores, sendo que muitos deles encontram-se na forma como foi feita a colonização das diferentes regiões do País e na constituição de sua base econômica. Segundo Leff (1972), por exemplo, a maior produtividade do Sudeste na produção de café e o maior cínamismo desse produto nos mercados externos, em comparação aos produtos do Nordeste (açúcar e algodão, sobretudo), estão na origem das desigualcaades entre essas duas regióes já no próprio século XIX. Embora outros autores, como Denslów (1973), discordem dessa origem, é inegável a sua importância.

A ocupação do espaço brasileiro se fez, predominantemente, na região litorânea, junto aos portos de exportação. Mais tarde, a população foi penetrando no interior do País, em busca principalmente de minérios, madeiras e terras férteis.

Originalmente, os centros que mais rápido prosperaram foram os que possuiam maior área polarizada, como São Paulo e Rio de Janeiro. No caso da antiga capital federal, o desenvolvimento foi explicado, em grande parte, pelas atividades administrativas do setor público.

Do lado paulista, os fatores mais importantes pelo aumento das ciesigualdades regionais no Brasil foram, entre outros, a existência de um produto dinâmico de exportação, o desenvolvimento da rede ferroviária interna e a existência de um mercado local de tamanho considerável.

O café foi um produto die grancie força industrializante para o Brasil como um todo e beneficiou a região onde sua produção mais se con- 
centrava. Seus efeitos sobre a indústria eram muito importantes pela elevada renda gerada, não apenas em forma de lucros para os fazendeiros, torrefadores, comerciantes e exportadores, mas, principalmente, pela massa salarial criada nas cidades e no campo, que formava um amplo mercado interno de consumo para bens manufaturados.

O desenvolvimento da rede ferroviária interna deu-se, basicamente, em resposta às necessidades cie transporte do café das zonas produtoras ao porto de Santos e à cidade de \$ão Paulo, principal centro consumidor e financeiro. $O$ café, como principal sustentáculo das exportações brasileiras, mereceu amplo apoio do Governo Federal na implantação de uma infra-estrutura de transportes, visando facilitar seu escoamento aos mercados externos. Esses investimentos beneficiaram, também, as atividades de mercado interno. Para citar um exemplo, lembremos que, nos primórdios do desenvolvimento da economia paulista, grande parte do café de São Paulo era exportado pelo porto do Rio de Janeiro, dinamizando o setor terciário daquela cidade. Com a criação da estrada de ferro Santos-Jundiaí, interligando a estrada de ferro existente até Ribeirão Preto, passando por Campinas, toda a região Oeste de São Paulo passou a exportar sua produção pelo porto de Santos, trazendo grande impulso para a cidade de São Paulo, futuro pólo nacional de desenvolvimento.

São Paulo tinha, desde ó início, uma grande vocação para tornarse um pólo urbano-industrial, pois era local de passagem dos diversos caminhos do Sul e do Centro-Oeste que levavam à Capital Federal e às zonas de exploração mineira. Destarte, sua proximidade do grande centro consumidor da época, a cióade do Rio de Janeiro, e a grande disponibilidade de terras férteis, aglutinancio uma população interiorana considerável, contribuíram para a expansão econômica e a consolidação futura da hegemonia de São Paulo (ver Singer, 1974). ${ }^{3}$

Do ponto de vista do Rio Grande do Sul, alguns fatores podem ser destacados como sendo muito importantes para o aumento das desigualdades no nivel de seu desenvolvimento em relação a São Paulo: inexistência de um produto dinâmico de exportação, pequena diimensão do mercado interno e escassez de insumos estratégicos.

A falta de um grande produto de exportação, como o café, impediu

3 Do lado do Nordeste, a estrutura fundiária concentrada e a baixa fertilidade do solo são alguns dos fatores que contribufram para aumentar os desniveis do desenvolvimento regional no Brasil. A esse respeito, ver, por exemplo, Leff (1972), Denslow (1973), Singer (1974), Andrade (1877), etc. 
a inserção do Rio Grande do Sul nas grancies correntes do comércio mundial, descie o início do século, quando ocorreram grandes transformações tecnológicas na indústria. A depenciência da economia gaúcha ao mercado nacional, menos dinâmico do que o mercado internacional e igualmente sujeito às vicissitudes deste, enquanto economia reflexa, manteve o Rio Grande do Sul a mercê de políticas públicas adversas, principalmente as relativas a crédito e a preço. ${ }^{4}$

Por outro lado, a economia gaúcha esteve muito presa à produção pecuária, característica do latifúndio extensivo, muito menos produtiva do que as lavouras comerciais, ern termos de valor da produção por ărea utilizada, contribuindo, amplamente, para a perda de sua posição em relação à economia paulista.

Um dos fatores explicativos do menor dinamismo do mercado interno gaúcho foi a escassa mão-de-obra rural assalariada, existente tanto na zona da pecuária extensiva, como nos minifúndios de subsistência. A grande distância dos maiores centros consumidores nacionais, como Rio de Janeiro e São Paulo, tornava a maioria dos produtos gaúchos pouco competitivos no mercado nacional. As empresas gaúchas contavam, em grande parte, com o pequeno mercado local, uma vez que as dificuldades de transportes, em termos de tempo e de custo; dificultavam as exportações para os demais estados.

A mentalidade agropastoril das lideranças locais, no passado, mais rentista do que capitalista, pouco abertas às mudanças e, portanto, à inciustrialização e ao desenvolvimento, explica, pelo menos em parte, a razão pela qual o Governo Estadual atrasou-se na elaboração de uma política industrial com incentivos que efetivamente atraissem as indústrias estrangeiras, ou de outros estados, e que desenvolvessem as in-

4 A polftica nacional, dominada por São Paulo, sobretudo até 1930, procurava beneficiar o café, principal base exportadora do Pals. Nas últimas décadas, com a aceleraçăo das taxas inflacionárias, a polftica de controle de preços dos alimentos intensificou-se, sob pretexto de combater a inflaçåo. Contudo, no passado, polfticas adversas para a pecuária gaúcha tambêm foram editadas pelo próprio Governo rio-grandense, sob a égide dos princĺpios positivistas: neutralidade (negavam-se créditos ou subsidios aos pecuaristas, porque nenhum grupo deve ser beneficiado, em detrimento dos demais); moralização ou austeridade (o Governo negava-se a tomar empréstimos e, por conseguinte, o orçamento público deveria ser equilibrado); progresso (dentro da "ordem" constitufda, deveria proceder-se a diversificaçăo $e$ a industrializaçăo da economia gaúcha). Por este último princípio, o Estado tinta o dever de intervir na economia, mas adotava "um intervencionismo conservador" $\theta$ limitado à implantaçăo de infra-estrutura de transporte. Ver, a esse respeito, Fonseca (1985, p.267 e 278). 
dústrias locais, já existentes. ${ }^{b}$ Além dísso, as indústrias gaúchas deparavam-se com altas tarifas de energia e com infra-estrutura básica deficiente, como energia, transporte, produtos siderúrgicos e outros insumos básicos.

Em razão desses fatores, compreencie-se porque o aumento da integração espacial da economia nacional beneficiou São Paulo, em detrimento das regiōes periféricas. Antes da integração, os diversos centros regionais de crescimento do País (São Paulo, Rio die Janeiro, Porto Alegre, Belo Horizonte, Recife, Salvador, Curitiba, etc.) eram constituídos por verdadeiras ilhas de desenvolvimento (Sinyer, 1974). No caso de muitos estacios, como o Rio Grande do Sul, Santa Catarina e o Paraná, a integração foi provocada pelo asfaltamento da BR-116, que possibilitou a colocação de produtos paulistas mais baratos e de melhor qualidade no Sul, reforçando o dinamismo do centro hegemônico, São Paulo, è causando efeitos regressivos à la Myrdal nos centros periféricos.

\section{POLARIZAÇÃO E DESPOLARIZAÇÃO DA INDÚSTRIA BRASILEIRA}

Em 1920, São Paulo detinha 30,4\% do pessoal ocupado no setor industrial brasileiro, contra 26,1\% para o caso do Estado do Rio de Janeiro e da Guanabara, juntos, e 9,3\% para o Rio Grande do Sul (Censo Industrial do Brasil de 1920). Conforme a tabela 1, a concentração industrial em São Paulo foi intensa na década de quarenta $(+10,9 \%)$, desacelerando-se nas décadas de cinqüenta $(+7 \%)$ e sessenta $(+2,1 \%)$, tornando-se negativa nos anos setenta $(-9,2 \%$, no período).

A participação atual do Estado do Rio de Janeiro na renda gerada no setor industrial do Brasil é declinante, passando de $26,9 \%$ em 1939 , para $17,0 \%$ em 1960 e para $11,9 \%$ em 1980 . Observa-se que o declínio do segundo maior centro industrial do País é anterior à mudança da capital federal para Brasília.

5 Embora o Partido Republicano Rio-Grandense (PRR) se embasasse no positivismo e, portanto, na industrializaçăo como forma de obtençăo do progresso material, ele sotria uma grande oposiçăo das elites agrárias locais, que consideravam alguns setores da indústria como artificiais e que, por conseguinte, năo podiam receber apoio oficial (Pesavento, 1986, p.5). Os fazendeiros da Campanha, como lembrou Fonseca (1980, p.141), constitulam foco de resistência ao positivismo, o que culminou com as revoltas armadas de 1893 e 1923. Além disso, os positivistas eram contrários a modificaçరos mais profundas na ordem económica e social, como atestam as mensagens de Börges de Medeiros à Assembléia de Representantes, durante seu longo perlodo como Governador do Estado (Pesavento, 1979, p.207). 


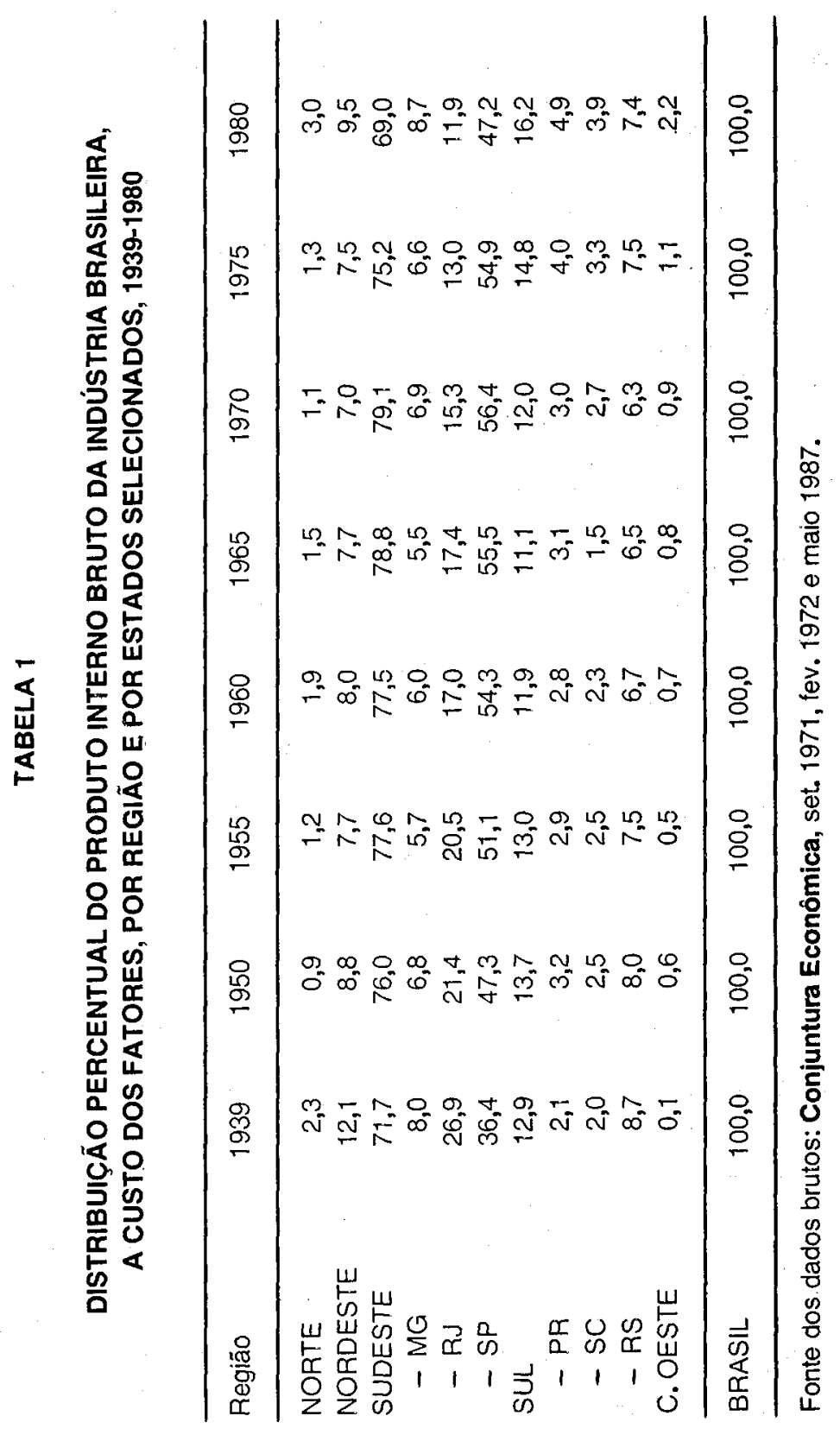


A participação do RS na formação da renda industrial brasileira é declinante até 1970. Na década de setenta sua posição melhora, permanecendo estável após 1975. Após 1970, constata-se, também, que a participação na formação da renda industrial nacional aumentou para as regióes Norte, Nordeste e Sul e para o Estado do Paraná, sendo decrescente para a região Sudeste. No caso de Santa Catarina, o aumento dessa participação vinha ocorrendo desde 1965 e da Região CentroOeste desde 1955. Embora se possa dizer que a participação da renda da indústria paulista na renda da indústria brasileira tenha permanecido relativamente constante na década de sessenta, em torno de $55 \%$, o início da reversão da polarização São Paulo-resto do Pais processou-se nessa década. De fato, pela tabela 2, constata-se que o ponto de máxima concentração da renda industrial em São Paulo ocorreu em 1968. Com base nesses dados, pode-se afirmar que a despolarização do crescimento industrial da economia paulista, em relação ao resto do País, teria ocorrido justamente quando começa o período do "milagre", no qual a economia brasileira como um todo cresceu a altas taxas. ${ }^{6}$

\section{TABELA 2}

\section{PARTICIPAÇÃo PERCENTUAL DA REGIÃO SUDESTE, DE SÃO PAULO, DO RIO DE JANEIRO E DO RIO GRANDE DO SUL NO PRODUTO INTERNO BRUTO DA INDÚSTRIA BRASILEIRA, A CUSTO DOS FATORES, ENTRE 1965 A 1970}

\begin{tabular}{lrrrrrr}
\hline ESTADOS & 1965 & 1966 & 1967 & 1968 & 1969 & 1970 \\
\hline SUDESTE & 78,8 & 79,9 & 80,6 & 80,9 & 80,3 & 79,1 \\
- SÃO PAULO & 55,5 & 55,6 & 55,0 & 56,8 & 55,9 & 56,4 \\
- RIO DE JANEIRO & 17,4 & 16,6 & 18,3 & 16,7 & 16,3 & 15,3 \\
RIO GRANDE DO SUL & 6,5 & 6,0 & 5,8 & 5,9 & 5,7 & 6,3 \\
\hline
\end{tabular}

Fonte dos dados brutos: Conjuntura Econômica, dez. 1973.

6 A reversão da polarizaçăo parece ocorrer igualmente dentro do Estado de Săo Paulo, a partir da capital, seguindo os eixos formados pelas grandes rodovias. A participação da Grande Sáo Paulo no valor adicionado da indústria paulista cailu de $70,48 \%$ em 1975 , para $59,65 \%$ em 1986. a Baixada Santista, incluindo a zona portuária $e$ a cidade de Cubatăo, também perderam participaçáo no perfodo $(4,75 \%$ para $3,36 \%)$. As regióes onde houve maior crescimento industrial, entre 1975 e 1986, foram as de Campinas, Ribeirăo Preto e Sorocaba. A participaçăo dessas três regióes no valor adicionado da indústria paulista, evoluiu de 16,33\% em 1975 para 26,59\% em 1986 (ver Azzoni, mimeo, p.5). 
A tabela 1 indica, ainda, que a perda de posição do RS foi mais acentuada na década de cinqüenta, quando se verificou intensa industrialização no Sudeste brasileiro, sobretudo em São Paulo, do que posteriormente. Entre 1981 e 1987, segundo os índices da produção industrial do IBGE, a indústria gaúcha cresceu $20,05 \%$, contra $18,94 \%$ para São Paulo e $15,6 \%$ para o Rio de Janeiro, no mesmo período. Contudo, esse crescimento ficou aquém da média nacional $(22,65 \%)$ e foi inferior ao desempenho da indústria mineira $(24,86 \%)$ e nordestina $(25,86 \%)$ (ver Bandeira, 1988, p.109). Essa despolarização decorre, também, dos incentivos fiscais e da luta dos demais estados brasileiros em obter investimentos federais e internacionais para suas respectivas áreas.

A redução das desigualdades regionais é mostrada, também, na tabela 3, onde se observa a inclusão de Santa Catarina, em 1980, como um dos estados brasileiros onde a renda per capital supera a média nacional. Entre 1970-75 a renda per capita que mais cresceu foi a do Paraná e entre $1975-80$ foi a da Região Norte.

\section{TABELA 3}

\section{RENDA PER CAPITA DAS REGIÕES BRASILEIRAS E DE ESTADOS SELECIONADOS EM 1970, 1975 E 1980 E TAXA DE VARIAÇÃO DA RENDA PER CAPITA ENTRE 1970-1975 E ENTRE 1975-1980 (NCZ 1.000,00 DE 1980)}

\begin{tabular}{lrrrrc}
\hline & \multicolumn{3}{c}{ Renda Per-Capita } & & \multicolumn{2}{c}{ Taxa de Crescimento } \\
\cline { 2 - 6 } REGIÖES & 1970 & 1975 & 1980 & $1970 / 75$ & $1975 / 80$ \\
\hline NORTE & 26,79 & 34,33 & 62,87 & 28 & 83 \\
NORDESTE & 18,31 & 26,53 & 39,93 & 45 & 51 \\
SUDESTE & 70,00 & 100,84 & 137,21 & 44 & 36 \\
- MG & 31,09 & 51,35 & 80,48 & 65 & 57 \\
- RJ & 76,65 & 85,10 & 137,03 & 11 & 61 \\
- SP & 95,22 & 132,82 & 172,00 & 39 & 29 \\
SUL & 44,23 & 74,17 & 103,80 & 68 & 40 \\
- PR & 34,17 & 64,84 & 88,67 & 90 & 37 \\
- SC & 40,97 & 64,77 & 104,38 & 58 & 61 \\
- RS & 56,12 & 87,85 & 118,41 & 56 & 35 \\
C. OESTE & 31,53 & 49,68 & 77,92 & 58 & 57 \\
\hline BRASIL & 46,07 & 68,32 & 95,97 & 48 & 40 \\
\hline
\end{tabular}

Fonte dos dados brutos: Conjuntura Económica, maio 1987. 


\section{POLARIZAÇAO E DESPOLARIZAÇAO INDUSTRIAL NO RIO GRANDE DO SUL}

O Estado do Rio Grande do Sul pode ser dividido, grosso modo, em três regiões agrícolas distintas: a primeira, na Depressão Central, que se estende de Porto Alegre a Uruguaiana, onde o principal produto é o arroz irrigado; a segunda, ao Norte da Depressão Central, constituída pelas antigas colônias de imigrantes italianos e alemães, onde predomina uma agricultura de pequenas propriedades; e a terceira, na Campanha, ao Sul da Depressão Central, constituída basicamente pela pecuária extensiva.

No início da colonização gaúcha, predominou a Região Sul, constituída pela economia do couro e do charque, onde os centros urbanos principais eram as cidades de Pelotas e de Rio Grande. Com a chegada dos colonos alemães, em 1824, ocupou-se a Região Central, ao leste de Porto Alegre, em direção de São Leopoldo e Novo Hamburgo. Desenvolveram-se a cultura do arroz irrigado e as primeiras incústrias. Posteriormente, chegaram os imigrantes italianos e de outras nacionalidades, que foram assentados na Região Norte do Estado. O escoamento da produção em direção ao Sul, na área do couro e do charque, passava por Porto Alegre que, cedo, tornou-se o centro hegemônico gaúcho.

A concentração industrial no município de Porto Alegre processouse, paulatinamente, até 1970. Em 1939, a capital gaúcha concentrava $17,57 \%$ da renda interna do Estado. Em 1970, essa participação atingiu 24,8\%, declinando para 22,08\% em 1980 (FEE, apud Alonso \& Bandeira, p.18).

O processo de despolarização do município de Porto Alegre, a partir da década de setenta, pode ser visto também pela sua participação no retorno do ICM aos municípios, cujo percentual caiu de $21,5 \% \mathrm{em}$ 1976 para 11,8\% em 1987 (Secretaria da Fazenda-RS; apud Alonso \& Bandeira, p.18). Considerando-se o valor adicionacio do ICM, essa participação aumentou, entre 1972 e 1986, tanto para o resto da Região Metropolitana de Porto Alegre (de $48,1 \%$ para $51,4 \%$ ), como para o resto do interior $(48,1 \%$ para $55,2 \%$ ) (Secretaria da Fazenda-RS, apud Alonso \& Bandeira, p.21).

A tabela 4 mostra a participação dos principais municípios do RS e da microrregião de Porto Alegre no emprego industrial do Rio Grande do Sul, na década de setenta. Constata-se a despolarização da capital gaúcha e da própria microrregião de Porto Alegre, que contavam, res- 
pectivamente, com $22,8 \%$ e $49,2 \%$ do emprego industrial do Estado em 1970 , participação que caiu para $15,2 \%$ e para $44,7 \%$, na mesma ordem.

Observa-se o aumento da participação no emprego industrial gaúcho dos municípios de Caxias do Sul (pólo metal-mecânico), Canoas, Pelotas (agroindústrıa alimentar), São Leopoldo e Sapiranga (calçados). Novo Hamburgo (calçados), que, em 1970, era o segundo centro industrial do Rio Grande do Sul, passou para o terceiro lugar, após Caxias do Sul, por ter perdicio participação no período. Rio Grande ("superporto") e Sapucaia do Sul, na Regiāo Metropolitana, perderam participação, enquanto Santa Maria e Passo Fundo (centros de serviços) mantêrn constante seu percentual no emprego industrial do Estado.

\section{TABELA 4}

\section{PARTICIPAÇÃO PERCENTUAL DE MUNICIPIOS SELECIONADOS E DA MICRORREGIÃO DE PORTO ALEGRE NO TOTAL DO PESSOAL OCUPADO NA INDÚSTRIA DO RIO GRANDE DO SUL, 1970, 1975 E 1980}

\begin{tabular}{lrrr}
\hline MUNICÍPIOS & 1970 & 1975 & 1980 \\
\hline Canoas & 3,3 & 3,6 & 3,5 \\
Caxias do Sul & 6,7 & 9,1 & 9,4 \\
Novo Hamburgo & 7,7 & 7,4 & 7,3 \\
Passo Fundo & 1,1 & 1,1 & 1,0 \\
Pelotas & 3,5 & 4,7 & 4,9 \\
Porto Alegre & 22,8 & 19,8 & 15,2 \\
Rio Grande & 2,3 & 2,2 & 1,8 \\
Santa Cruz do Sul & 1,4 & 1,7 & 1,7 \\
Santa Maria & 0,9 & 1,0 & 0,9 \\
São Leopoldo & 3,3 & 3,0 & 3,5 \\
Sapiranga & 1,9 & 2,2 & 3,2 \\
Sapucaia do Sul & 2,5 & 1,9 & 1,7 \\
SUBTOTAL & 57,4 & 57,7 & 54,1 \\
Microrreg. P. Alegre & 49,2 & 46,1 & 44,7 \\
TOTAL RS & 100,0 & 100,0 & 100,0 \\
\hline
\end{tabular}

Fonte dos dados brutos: Ćenso Industrial do RS: 1970, 1975 e 1980 
A perda de participação de Novo Hamburgo, município importante na periferia da Região Metropolitana, deve-se, em grande parte, à dispersão das empresas produtoras de calçados e outros artigos de couro, no interior do Vale dos Sinos e cidades vizinhas, em busca, sobretudo, de mão-de-obra mais barata e em maior quantidade (ver Souza, 1982). Já no caso de Porto Alegre, o fenômeno é mais antigo, embora as entradas tenham compensado as saidas de empresas antes da década de setenta. $O$ fenômeno ocorreu naturalmente, via mercado, com o asfaltamento e posterior duplicação da BR-116, em direção de Novo Hamburgo.

A descentralização de muitas firmas industriais ocorreu em razão da falta de espaço para expansão no centro e do alto custo dos terrenos. Na periferia, as empresas dispóem de terrenos mais baratos e mais espaçosos para edificações maiores, para estocar materiais, manobrar caminhöes e expandir-se no futuro. Citamos, como exemplo, o caso das Indústrias Micheletto (tornos mecânicos e parafusos) que estavam localizadas na Rua Sarmento Leite, praticamente no centro de Porto Alegre, e que foram para Canoas; a Siderúrgica Riograndense (ferro para construção e arames para cercas) que, mantendo a pequena usina inicial na Av. Farrapos, construiu uma grande filial em Sapucaia; a Companhia Geral de Indústrias (fogões e parafusos), que transferiu parte de sua fábrica da Av. Bento Gonçalves para o município de Guaíba. Além das empresas que se descentralizaram de Porto Alegre, outras surgiram no próprio eixo de crescimento referido. Constituem exemplos, as Construções Eletro-Mecânicas e a Refinaria Alberto Pasqualini da Petrobrás, em Canoas, a Pirelli, em Sapucaia, etc. Convém mencionar, também, a existência de distritos industriais em Cachoeirinha e em Gravataí, ${ }^{7}$ na Região Metropolitana, que acolheram inúmeras empresas de Porto Alegre, que desejavam expandir-se, mas não encontravam condições na capital. Essa despolarização, beneficiando as cidades da periferia metropolitana, começa a preocupar as autoridades de Porto Alegre, pela evasão fiscal e pelo enfraquecimento do efeito multiplicador da renda $e$ do emprego sobre as atividades industriais ligadas, o comércio e os ser-

7 Esses distritos industriais foram implantados pela CEDIC, da Secretaria da Indústria e Comércio do Estado do RS. Esse órgão estå criando um distrito industrial em Alvorada, que avança no município de Viamáo, e está planejando outro para Canoas. Em Porto Alegre, a Prefeitura Municipal estuda a implantaçăo de um distrito industrial na Vila Restinga, na zona sul do municlpio. 
viços. ${ }^{8}$

No Brasil, procurou-se reforçar a posição das nove áreas metropolitanas, para contrabalançar o peso de São Paulo. Em nivel regional, tentou-se dotar as cidades médias com infra-estruturas; para "filtrar" as migrações dos fatores do campo e das pequenas cidades em direção das áreas metropolitanas. ${ }^{9}$

\section{REVERSÃO DA DESPOLARIZAÇÃO E REDUÇÃO DO FLUXO MIGRATÓRIO}

A despolarização, que parece estar ocorrendo em nível nacional, reflete as deseconomias externas surgidas nos grandes centros e as economias líquidas, positivas, da periferia. Este último fato se deve aos incentivos fiscais concedidos fora dos centros maiores, como a implantação da Zona Franca de Manaus, as concessões de recursos federais para as agências regionais de ciesenvolvimento, como SUDENE, SUDAM, etc., a alocação de grancues projetos nas regiões menos industrializadas do País, como os pólos petroquímicos da Bahia e do Rio Grande do Sul, os investimentos nos transportes, energia e comunicações e o próprio crescimento econômico geral que generaliza a industrialização em tocio o espaço.

Constatada a tendência à despolarização, cabe perguntar se o fenômeno será persistente e se apresenta aspectos negativos. A descen-

8 O crescimento por pólos pode significar despolarizaçáo do centro principal. Nesse sentido, ele coincide com a idéia de despolarização. Na inglaterra e França, a política de despolarização das economias nacionais tem como objetivo desafogar a concentração demográfica e económica de Londres e de Paris. Essa polftica consistiu na criaçåo de cidades novas (14 na Inglaterra e 5 na França) e na implantaçáo de infra-estrutura básica em metrópoles regionais definidas como de equilíbrio (8 na França). Nesse último pals, implantou-se, tarnbém, centros nodais restruturadores da periferia da região metropolitana de Paris, com o objetivo de desafogar o centro urbano tradicional. Essas cidades novas, metrópoles de equilibrio e centros reestruturadores de arrebaldes são distribuidos estratégicamerite no espaço a determinada distância do centro principal, formando anéis e obedecendo, tanto quanto possível, à distribuiçăo inicial da populaçăo e da rede de transportes.

9 Outra estratégia visando, não a despolarizaçăo em si, mas a criação de empregos industriais em regiőes com depressão, constituindo focos de emigraçăo, são os distritos industriais. Eles consistem, basicamente, no loteamento e terraplenagem de uma determinada área, destinada à localização das indủstrias, na implantaçăo de uma infra-estrutura básica para as empresas, como ruas pavimentadas, energia, centrais de telefone e telex, centrais de matérias-primas, apoio creditfcio, isençáo de impostos e outros incentivos. Os primeiros distritos industriais foram criados após a Segunda Guerra Mundial, embora, na Inglaterra, já houvesse estimulos semelhantes para gerar emprego nas regiőes devastadas pela Grande Depressão na década de trinta. 
tralização poderá encetar, em primeiro lugar, uma reação nos centros maiores, através de políticas industriais visando reverter a perda de sua participação. Isso poderá engendrar uma industrialização mais seletiva, englobando atividades não-poluentes e de tecnologia superior. Aliás, a própria despolarização pode ser conseqüência do processo de "filtragem" quando atividades de tecnologia menos sofisticada deslocam-se para a periferia, em busca de mão-de-obra mais barata e abundante, bem como de terrenos mais baratos e de maior dimensão, obtendo essas vantagens com menor acessibilidade ao centro urbano principa! e outras vantagens aglomerativas. Nas últimas décadas, novos processos e novos materiais, bem como o desenvolvimento geral dos meios de transporte e comunicação, têm reduzido a participação do custo de transporte no custo total dos produtos. Assim sendo, a localização das atividades tornou-se mais livre, abrangendo círculos maiores a partir do centro de negócios tradicional. Isso explica a dispersão das empresas industriais para as periferias das regiões metropolitanas e para as cidades próximas, principalmente ao longo das vias de rápido acesso ao centro principal. ${ }^{10}$

Em segundo lugar, se a descentralização das indústrias ocorrer a partir de metrópoles regionais em razão de incentivos fiscais concedidos na periferia mais distante do centro principal, ou por ausência de uma política industrial efetiva em tais centros (despolarização precoce), isso poderá implicar uma situação de subótimo no sentido de Pareto, isto é, o crescimento da economia como um todo poderia ser superior se a despolarização ocorresse mais tarde.

No caso de Porto Alegre e de sua região metropolitana a despolarização precoce poderá estar ocorrendo. A fuga de suas indústrias para o interior do Estado, com a conseqüente "desindustrialização" da capital, evasão fiscal e desemprego, poderá prejudicar o desempenho da economia gaúcha em seu conjunto. Uma região metropolitana de seu porte, com aproximadamente dois milhões de habitantes, apresenta externalidades importantes, podendo elevar a taxa de retorno do investimento, possibilitando maior grau de competição em relação aos demais estados do Brasil.

10 Azzoni calcula que empresas localizadas em um raio de $150 \mathrm{~km}$ de São Paulo continuam utilizando amplamente os serviços oferecidos pela capital. Os escritórios centrais das empresas permanecem no Centro, descentralizando-se filiais em toda a região metropolitana e no interior dó Estado. Segundo ele, este seria um processo de "desconcentração concentrada" e não uma verdadeira despolarização (ver Azzoni, 1986, p. 126). 
Essa despolarização pode ser contrabalançada com a criação de áreas industriais na própria cidade de Porto Alegre, para abrigar, sobretudo, indústrias ce tecnologia relativamente mais avançada, como por exemplo informática, aeronáutica, eletrônica e outras atividades de "ponta", não-poluentes e ligadas à pesquisa universitária, face à maior concentração populacional e os preços mais elevadios dos terrenos.

A localização de novos distritos industriais na Região Metropolitana precisaria levar em conta o processo geral ae ocupação do solo pela população, pelo comércio e pelos serviços. Novas rodovias de pista dupla, de penetração, no estilo da BR-116, assim como rodovias circulares do estilo da que liga Viamão, Gravatai e Esteio, precisariam ser implementacias, para aumentar a acessibilidacie ao Centro a partir cie novos pontos da periferia, como por exemplo de Alvorada, Viamão, Vila Restinga. Esses eixos auicionais auxiliariam, também, a desenvolver outras áreas cia periteria metropolitana, sobretuco as de maior densidade demográfica. ${ }^{11}$

Porto Alegre teria condições, igualmente, de crescer ao sul, em direção da Vila Restinga, aglomeração no município de Porto Alegre que conta com cerca e 100 mil habitantes, com vida própria, mas sem indústrias. $^{12} \mathrm{O}$ crescimento urbano-industrial precisa efetuar-se de modo a ciesobstruir o centro urbano, prensado junto ao Rio Guaíba, e desafogar as zonas industriais ao norte da cidade, congestionadas a partir do centro urbano.

Todavia, o dilema que se apresenta é que as cidades do interior precisam continuar industrializando-se, para evitar as migrações excessivas em direção de Porto Alegre e de sua Região Metropolitana. A questão é, principalmente, adequar o crescimento do interior às suas características, promovendo, por exemplo, maior grau de agroindustrialização. Desse modo, tanto o setor agrícola, como as pequenas cidades do interior, crescendo mais, poderiam reter a população em suas áreas respectivas. As cidades médias exerceriam, igualmente, uma "filtragem"

11 A implantação da auto-estrada Porto Alegre-Osório ainda não constituiu um verdadeiro eixo de desenvolvimento pela baixa densidade demográfica e pelas dificuldades de urbanizaçăo em terrenos alagadiços, às suas margens, exceto Cachoeirinha e Gravatal, que ficam à proximidade, mas um pouco mais distante de Porto Alegre, na altura do anel rodoviário que liga Viamåo a Esteio, passando por Gravatal.

12 A acessibiliciade da Vila Restinga a Porto Alegre e aos demais centros da Regiáo Metropolitana poderia concretizar-se peto prolongamento do anel rodoviårio Esteio-Viamäo, aproveitando a estrada precárı já existente. Esse anei náo congestionaria a atual via de acesso da zona sul ao centro de Porto Alegre, passando por vários bairros residenciais. 
das migrações que, eventualmente, fluiriam em direção de Porto Alegre e sua região.

Essa "filtragem" dos fatores capital e trabalho - redução do fluxo migratório - pode ser efetuada, pois, não apenas pela implantação de infra-estrutura básica nos centros urbanos menores, mas, principalmente, pela maior assistência ao trabalhador rural e pelo desenvolvimento de atividiades vinculadas à agricultura em tais centros (ver SOUZA, 1988, cap.6).

Nesse sentido, temos a experiência do BNDES em Palmares, a $100 \mathrm{~km}$ de Porto Alegre, onde esse banco, através do FINSOCIAL, concedeu empréstimos para eletrificação de minifúnaios e abertura de poços artesianos para irrigação de lavouras de arroz: Para cada minifúndio, o investimento foi de 500 OTN's e o retorno corresponcia à elevação da renda do agricultor de 50 a $200 \%$, enquanto a criação de um único emprego na indústria custava de 5 a 6 mil OTN's (Zero Hora, 25/9/88). Dessa forma, 280 propriedades rurais, com áreas variandio entre 5 a 6 hectares, foram eletrificadas em Palmares, sendo 18 com poços artesianos. ${ }^{13}$

Outro exemplo digno de nota, um pouco mais antigo, são os condomínios para criação de suínos em pequenas propriedades em Santa Catarina. Projetos desse tipo, não apenas evitam maior expansão das favelas nos grandes centros urbanos, aumentando os índices de subdesenvolvimento (criminalidade, mortalidade infantil, promiscuidade, subhabitaçāo, etc.), elevando os gastos públicos, como aumentam o bemestar das populações rurais, integrando-as nos circuitos da economia moderna, fazendo com que a agricultura cumpra uma de suas funções mais nobres: constituir mercado para bens industriais, integrando os setores agrícola e inciustrial, a área urbana com a rural, descentralizando o desenvolvimento econômico e realizando uma verdadeira despolarização do crescimento, da cultura e do desenvolvimento econômico.

\section{BIBLIOGRAFIA}

\section{ALONSO, José A.F. \& BANDEIRA, Pedro S. A "desindustrializaçāo" de}

13 E interessante mencionar que, após a implantação desse projeto, administrado pela preteitura local, 150 famflias retornaram das favelas de Porto Alegre, para cultivarem suas terras. Quase todos os agricultores beneficiados pintaram suas casas e compraram um aparelho de televisấo. Isso corresponde a uma revoluçăo na cultura camponesa e nos seus padrő́es de consumo. 
Porto Alegre: Causas e Perspectivas. Ensaios FEE, Porto Alegre, S(1):3-28, 1988.

ANDRADE, Thompson A. Desequilibrios Regionais no Brasil: uma Seleção de Estudos Empíricos. In: SCHWARTZMAN, Jacques. Economia Regional, Textos Escolhidos. Belo Horizonte, CEDEPLAR, 1977, p.117-135.

AZZONI, Carlos R. Indústria e Reversão da Polarização no Brasil. São Paulo, IPE/USP, 1986.

— . Novo Endereço da Indústria Paulista. São Paulo, IPE/USP, 14 fl. (mimeo).

BANDEIRA, Pedro S. O Rio Grande do Sul e as Tendências da Distribuição Geográfica do Crescimento da Economia Brasileira, 1940-1980. Porto Alegre, FEE, 1988. 115p.

CAMPOS, Roberto de Oliveira. Planejamento do Desenvolvimento Econômico de Países Subdesenvolvidos. Digesto Econômico. São Paulo, vol. 89, p.11-22, abr. 52 e 90, p.20-38, maio 1952.

CANO, Wilson. Desequilibrios Regionais e Concentração Industrial no Brasil 1930-1970. São Paulo, Global, UNICAMP, 1985. (Cap. 1, p.21-49).

CENSO INDUSTRIAL 1970, 1975 e 1980: Rio Grande do Sul. Rio de Janeiro, IBGE, 1974, 1979 e 1984.

CONJUNTURA ECONÓMICA. Rio de Janeiro, FGV, set. 1971, fev. 1972, dez. 1973 e maio 1987.

COUTINHO, Luciano. Desigualdades Regionais: uma Revisão da Literatura. Revista de Administração de Empresas, 13(3):63-75, jul./set. 1973.

DENSLOW, David. As Origens da Desigualdade Regional no Brasil. Estudos Econômicos, 3(1):65-88, 1973.

FONSECA, Pedro C.D. A Integração do Norte do RS à Economia Gaúcha. Perspectiva Econômica. São Leopoldo, 10(25):131-150, mar. 1980.

— . A Transição Capitalista no Rio Grande do Sul: A Economia Gaúcha na Primeira República. Estudos Econômicos, São Paulo, 15(2):263-289, maio/ago. 1985.

HADDAD, Paulo R. A Economia Regional no Brasil: Velhas Dimensões, Novas Perspectivas. Análise Econômica. Porto Alegre, FCE/ UFRGS, 7(11):131-48, mar. 1989.

KUZNETS, Simon. Quantitative Aspects of the Economic Growth Nations: Distribution of Income by Size. Economic Development and Cultural Change, 11(2), Jan. 1963. 
LEFF, N. Desenvolvimento Econômico e Desigualdade Regional: Origens do Caso Brasileiro. Revista Brasileira de Economia, 26(1):3-21, jan./mar. 1972.

MARSHALL, Alfred. Princípios de Economia: Tratado Introdutório. "São Paulo, Abril Cultural, 1982. (Primeiro volume, cap. X).

MYRDAL, Gunnar. Teoria Econômica e Regiões Subdesenvolvidas. Rio de Janeiro, Saga, 1968. 240 p.

PERROUX, François. O Conceito de Pólos de Crescimento. In: SCHWARTZMAN, Jacques. Economia Regional: Textos Escolhidos. Belo Horizonte, CEDEPLAR, 1977, p. 145-56.

PESAVENTO, Sandra. Rio Grande do Sul, 1890-1930: a Idéia da Indústria (com a Palavra o Empresário e o Governo). Análise Econômica, Porto Alegre, 4(7):3-20, nov. 1986.

— República Velha Gaúcha: Estado Autoritário e Economia. In: DACANAL, José H. \& GONZAGA, Sérgius. RS: Economia \& Política. Porto Alegre, Mercado Aberto, 1979, p. 193-228.

RECENSEAMENTO DE 1920: Brasil, Indústria. Rio de Janeiro, Diretoria Geral de Estatistica, s/d.

RICHARDSON, Harry W. Polarization Reversal in Developing Countries.

Papers and Proceedings of the Regional Science Association, $V$. 45, 1980.

SINGER, Paul. Desenvolvimento Econômico e Evolução Urbana: São Paulo, Ed. Nacional, 1974. 377p.

SMITH, Adam. A Riqueza das Nações: Investigação Sobre sua Natureza e suas Causas. São Paulo, Abril Cultural, 1983. 2 vol.

SOUZA, Nali de Jesus de. O Papel da Agricultura na Integração Intersetorial Brasileira. São Paulo, IPE/USP. 321p. (Tese dout. econ.)

- Agricultura e Integração Industrial no Brasil. Ensaios FEE, Porto Alegre, 9(2):46-63, 1988.

— Integração Econômica e Estratégias de Integração. Ensaios FEE, Porto Alegre, 10(1):105-33, 1989.

- Perfil e Fatores de Localização da Agroindústria Alimentar do Rio Grande do Sul. Porto Alegre, IEPE/UFRGS, 1990. 128p. (Relatório de Pesquisa n 41).

SOUZA, Nali J. et alii. Diagnóstico da Região da Encosta Superior

do Nordeste. Porto Alegre, Secretaria do Trabalho e Ação SocialRS, 1982. 394p.

WLLIMSON, Jeffrey G. Desigualdades Regionais e o Processo de Desenvolvimento Nacional: Descrição de Padrões. In: SCHWARTZMAN, 
Jacques. Economia Regional, Textos Escolhidos. Belo Horizonte, CEDEPLAR, 1977, p.53-116.

ZERO HORA. Caderno de Economia. Porto Alegre, 25 set. 1988 (última página, entrevista com Carlos Lessa).

\section{ABSTRACT}

\section{INDUSTRIAL POLARIZATION AND DEPOLARIZATION IN BRAZIL AND IN RIO GRANDE DO SUL}

This paper intends to examine a hypothesis of reversion of industrial polarization in Brazil, since the veginning of the 70's. With the use of industrial gross domestic product, generated in different regions of the Country, including the main urban centers, a rising inciustrial concentration is found in São Paulo until 1968, when it reaches a maximum, and thereafter a decline up to the presient. The depolarization also occurs in Rio Grande do Sul. The net loss of manufacturing plants located in Porto Alegre to the Metropolitan area's periphery and to the interior of the state occurs since the beyinning of the 70's. The study concludes that depolarization is a natural market phenomenon, although fiscal incentives given at the periphery accelerate this process, making it precocious, as it seems the case in Rio Grande do Sul. 